International Journal of Agriculture, Environment and Bioresearch

Vol. 4, No. 05; 2019

ISSN: $2456-8643$

\title{
BIODEGRADATION/ DECOLORIZATION OF SYNTHETIC DYES BY BACTERIAL ISOLATES
}

\author{
Rabia Omar Alghazeer ${ }^{1 *}$; Karima Massud Abuamer ${ }^{1}$; Asma Yousef Alnajjar²; Mohamed Khalifa Albahi ${ }^{3}$ \\ ${ }^{1}$ Department of Chemistry, Faculty of Science, University of Tripoli, Tripoli, Libya \\ ${ }^{2}$ Department of Soil and Water, Faculty of Agriculture, University of Tripoli, Tripoli, Libya \\ ${ }^{3}$ Department of Chemistry, Faculty of Sciences, Azzawiya University, Azzawiya, Libya.
}

http://doi.org/10.35410/IJAEB.2019.4439

\begin{abstract}
Many microorganisms are able to transform synthetic dyes to non-colored and/or completely mineralize products. This study deals with the ability of selected bacterial isolates to decolorize synthetic dyes (all selected dyes were tested at concentration of $25 \mathrm{ppm}$, Red food dye at concentration 1\%). Color removal was measured in cultures containing dyes incubated for 12 days. All isolates were weak in removing Methylene green, Nile blue, and Acridine orange from aqueous solutions. However Brilliant yellow, Congo red and Red food, were decolorized within 2-8 days. UV-VIS scan $(300-700 \mathrm{~nm})$ of culture supernatants showed decolorization and decrease in dye concentration at different incubation times. Decolorization of Brilliant yellow ranged from $99.78 \%$ to $100 \%$. While decolorization of Congo red ranged from $81.7 \%$ to $99.8 \%$. Highest decolourization capability by tested isolates was shown with Red food. These isolates can be used on the treatment of dye-containing wastewaters.
\end{abstract}

Keywords: Dye, biodegrdation, decolorization, bacterial isolates.

\section{INTRODUCTION}

Synthetic dyes are extensively used in many industries, such as dyestuffs, textile, plastics, paper, food, cosmetic and pharmaceuticals [1]. Synthetic dyes exhibit considerable structural diversity with high molecular weight and a complex structure, the structure, showing either a very low or no biodegradability [2]. The chemical classes of dyes applied on industrial scale are the azo, anthraquinone, sulfur, indigoid, triphenylmethyl (trityl), and phthalocyanine derivatives. Discharge of synthetic dyes into water bodies without any treatments may pose great environmental and health problems [3]. Therefore the influence [4] and toxicity [5] of dyes that are released in the environment have been extensively studied.

Traditional wastewater treatment technologies have proven to be markedly ineffective for handling wastewater of synthetic dyes because of the chemical stability of these pollutants [6]. Different methods are available for the remediation of dye wastewaters. These include physicochemical methods, like adsorption, chemical oxidation, precipitation, coagulation, filtration, electrolysis and photo-degradation methods. Most of these methods are costly and less efficient as well as their limited applicability and also they produce more wastes [7]. It is now 
known that several microorganisms including fungi, bacteria, yeasts and algae can decolorize and even completely mineralize many synthetic dyes under certain environmental conditions. The bacterial decolorization and degradation of these dyes have received increasing attention, since it can achieve a high degree of biodegradation and mineralization, in addition it is inexpensive and environmentally friendly $[8,9]$.

In the case of azo dyes decolorization, bacteria cleave the azo bond by azoreductase enzyme, results in decolorization of dye [10]. In comparison to fungal, bacterial decolorization is normally faster [11].

Decolorization of dyes may take place in two ways: either adsorption on the microbial biomass or biodegradation of the dyes by the cells [12]. Adsorption of dyes may occur on growing/living microbial cells as well as on dead microbial cells. While Biodegradation of synthetic dyes not only results in decolorization but also in mineralization of the dye molecules into smaller and simpler products which result from the action of the biotransformation enzymes [13]. Various strains attack dye molecule at different positions and decomposed products are used by another strain for further decomposition [14]. The aim of the current study was to determine the potential of some bacterial isolates in the decolourization of simulated wastewater effluents of selected dyes.

\section{MATERIALS AND METHODS}

\section{Dyes and chemicals}

All chemicals used were of analytical grade. The common names of all dyes have been used for convenience. Brilliant yellow was purchased from Riedel-de hean (Co, Germany), Congo red was obtained from (BDH Chemicals Ltd, Poole England), Methylene green was bought from Acros Organics (New Jersey, USA), Nile blue, Acridine orange were purchased from Sigma chemicals USA, and Red Food coloring contain E122 and E129 was obtained from (Carmoisine) (AromaTech, Tunisia). The specific characteristics of tested dyes are presented in Table 1. The nutrient agar and nutrient broth were obtained from BDH Chemicals (Poole, England).

\section{Preparation of dye stock solutions}

Dye stock solutions were prepared by dissolving accurately weighed dyes in distilled water to concentration of $25 \mathrm{ppm}$ for synthetic dyes, while red food dye (RF) was prepared in a concentration of $0.1 \%$. The stock solution was diluted accordingly to obtain solutions of desired concentrations.

\section{Sources of organisms}

Pseudomonas aeruginosa (P. aer), Proteus spp. (P. spp.), and klebsiella spp. (K. spp.), were obtained from the department of Microbiology, Faculty of Veterinary Medicine, University of Tripoli, Libya. Bacillus subtilis (B. sub) were kindly provided by Department of Microbiology Bio-technology Research Center, Libya, while Bacillus spp. (B. spp.) was isolated from soil samples taken from a municipal landfill. 
Table 1: Characteristics of selected dyes

\begin{tabular}{|c|c|c|c|c|c|}
\hline Dyes & Structure & $\begin{array}{l}\text { Molecular } \\
\text { formula }\end{array}$ & Group & $\begin{array}{c}\Lambda \max \\
(\mathrm{nm})\end{array}$ & Appearance \\
\hline $\begin{array}{c}\text { Methylene } \\
\text { green }\end{array}$ & & 364.85 & basic & 615 & Green \\
\hline Nile blue & & 353.85 & basic & 638 & Blue \\
\hline Acridine orange & & 301.8 & & 490 & Orange \\
\hline Congo red & & 364.85 & acidic & 498 & Red \\
\hline Brilliant yellow & & 624.55 & acidic & 402 & Yellow \\
\hline Red Food colour & & & & 635 & Red \\
\hline $\begin{array}{l}\text { [Allura Red } \\
\text { (E129), } \\
\text { Carmoisine } \\
\text { (E122)] }\end{array}$ & & $\mathrm{Na}^{\oplus}$ & & & \\
\hline
\end{tabular}




\section{Preparation of inoculua for liquid culture:}

Bacterial isolates were grown in $250 \mathrm{ml}$ Erlenmeyer flasks containing $25 \mathrm{ml}$ Nutrient broths under shaking condition and incubated at $30^{\circ} \mathrm{C}$ for $24 \mathrm{hr}$ in an incubator, prior to contact with dyes.

\section{Effects of different bacterial isolates on dye decolorization:}

Bacterial isolates were initially screened for their declorization activity with six structurally different dyes $(25 \mathrm{mg} / \mathrm{L})$ of: Brilliant yellow, Congo red, Methylene green, Nile blue, and Acridine orange; and of $(0.1 \%)$ Red food dye). The screening was carried out in liquid media (Nutrient broth). An aliquot of $100 \mathrm{ml}$ broth with $25 \mathrm{mg} / \mathrm{L}$ of dye content was taken in $250 \mathrm{ml}$ sterilized cotton plugged Erlenmeyer flask and was incorporated with homogenized bacteria inoculums (2x105 CFU). The flasks were incubated in an orbital shaker incubator (100 rpm) for maximum 12 days at 300C. A group of three flasks was operated in each experiment beside a control flask without bacterial inoculum.

\section{Effect of initial concentration of dye:}

The effect of three dye concentrations $(25,50$ and $100 \mathrm{mg} / \mathrm{L}$ for all dyes but RF in which were tested in concentrations of $0.1 \%, 0.2 \%, 0.4 \%$ ) on dye decolorization was investigated. Experiments were performed in $15 \mathrm{~mL}$ glass tubes containing $10 \mathrm{~mL}$ medium at $300 \mathrm{C}$ in an orbital shaker incubator $(100 \mathrm{rpm})$ for maximum 12 days. One set of the tube without inoculation was kept as control. Dye decolourization was estimated by measuring the absorbance at the respective (absorption maxima) Kmax of different dyes individually in UV-Vis Spectrophotometer on UV/Vis Spectrophotometers (PerkinElmer, LAMBDA 25, USA

\section{Decolorization by isolates on Food Red, Brilliant yellow and Congo red dyes}

A bacterial suspension was added into the medium and the decolorization extent was tested. Bacterial isolates without dye were added into the medium as a control. Both the experiments of decolorization by treated and untreated bacterial isolates were performed at $30^{\circ} \mathrm{C}$ at $100 \mathrm{rpm}$. After incubation for 8 days, samples from the control culture were centrifuged at $1000 \times \mathrm{xg}$ for 5 min and the supernatants were scanned in the range of $200-700 \mathrm{~nm}$ in a ultraviolet-visible (UVVis) spectrophotometer, in order to detect transformation of compounds in the medium.

\section{Measurement of decolorization extent}

Samples ( $4 \mathrm{~mL}$ ) were collected every $12 \mathrm{~h}$ and centrifuged at 8000xg for $5 \mathrm{~min}$. Decolorization extent was determined by measuring the absorbance of the culture supernatant at $\lambda 600 \mathrm{~nm}$ using a UV/Vis Spectrophotometers (PerkinElmer, LAMBDA 25, USA). (Fig. 1). Decolorization extent was calculated using the following equation:

Decolorization efficiency $(\%)=100 x\left(\mathrm{OD}_{\mathrm{i}}-\mathrm{OD}_{\mathrm{t}}\right) / \mathrm{OD}_{\mathrm{i}}$ 
Where ODi refers to the initial absorbance and ODt refers to the absorbance after incubation for an incubation time $\mathrm{t}$.
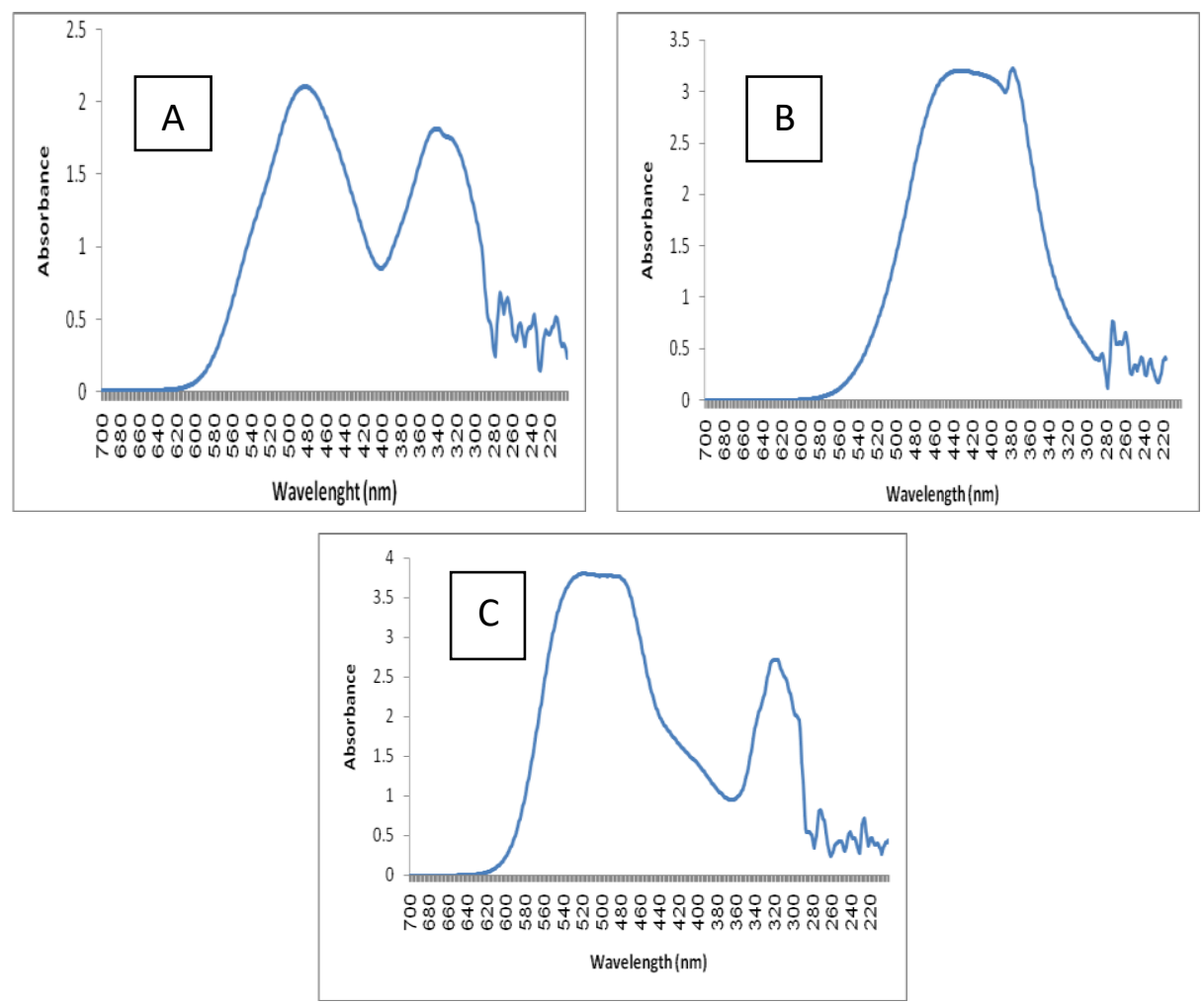

Fig. 1. Absorbance spectrum of Congo red (A), Brilliant yellow (B) and of Red food dye (C).

\section{Statistical analysis}

Data were expressed as means \pm standard deviations (SD) of triplicate determinations. Significance was assessed using one way ANOVA-in SPSS 16.0 (Statistical Package for the Social Sciences, SPSS Inc., Chicago, IL, USA). A probability value of $\mathrm{P}<0.05$ was considered significant.

\section{RESULTS}

Pseudomonas aeruginosa (P. aer.), Proteus spp. (P. spp.), klebsiella spp. (K. spp.), Bacillus subtilis (B. sub.) and Bacillus spp. (B. spp.) were incubated for 12 days and the effect of their culture on decolorization of Brilliant yellow, Congo red, Methylene green, Nile blue, Acridine orange and Red Food were tested.

Decolorization of dyes by different bacterial isolates 
The best decolorization rates were detected after incubating dyes with the isolates for 8 days (Table 2). There was no change in the $\mathrm{pH}$ in all cultures $(\mathrm{pH}=7.01)$ and a decrease in peak at the respective absorption maxima of all the three dyes (Brilliant yellow, Congo red and Red food) during incubation time which indicated that the color removal may related to the breakdown of the dyes. The higher decolorization rate for Brilliant yellow dye was obtained by P. aer. $(99.78 \%)$, P. spp. $(99.83 \%)$ and

B. spp. (100.04) but it was not significantly different $(\mathrm{P}>0.05)$. The highest decolorization levels for Congo red were obtained by P. aer. (99.80\%), K. spp. (99.80\%) and P. spp. (99.65\%) but it was also insignificantly different $(\mathrm{P}>0.05)$. In addition, all tested isolates exhibited a significant decolorization activity on RF in comparison with initial dye concentration (Table 2). However, tested isolates had little or no activity on Acridine orange, Methylene green and Nile blue.

Table (2). Decolorization (\%) of dyes by different bacterial isolates monitored during 8 days.

\begin{tabular}{|c|c|c|c|c|c|c|}
\hline & \multicolumn{6}{|c|}{ Decolorization (\%) } \\
\hline $\begin{array}{l}\text { Bacteria } \\
\text { isolates }\end{array}$ & $\mathbf{B Y}^{*}$ & $\mathbf{C R}^{*}$ & MG * & $\mathbf{N B}^{*}$ & AO * & $\mathbf{R F}^{* *}$ \\
\hline P. aer & $99.78 \pm 0.04^{\mathrm{a}}$ & $99.80 \pm 0.3^{\mathrm{a}}$ & $6.5 \pm 0.7^{\mathrm{b}}$ & $6.5 \pm 0.61^{\mathrm{a}}$ & $3.95 \pm 0.82^{\mathrm{a}}$ & $100.05 \pm 0.7^{\mathrm{a}}$ \\
\hline $\boldsymbol{K}$. spp. & $23.95 \pm 1.4^{\mathrm{b}}$ & $99.56 \pm 1.1^{\mathrm{a}}$ & $6.08 \pm 0.7^{b}$ & $7.14 \pm 0.14^{b}$ & $1.95 \pm 0.63^{b}$ & $99.85 \pm 0.04^{\mathrm{a}}$ \\
\hline B. sub & $99.96 \pm 0.19^{\mathrm{a}}$ & $4.63 \pm 0.24^{c}$ & $7.75 \pm 0.1^{\mathrm{a}}$ & $7.92 \pm 0.45^{b}$ & $3.82 \pm 0.56^{\mathrm{a}}$ & $99.86 \pm 0.37^{a}$ \\
\hline B. spp. & $100.04 \pm 0.21 \mathrm{a}$ & $81.78 \pm 0.8^{\mathrm{b}}$ & $6.80 \pm 0.4^{\mathrm{b}}$ & $7.01 \pm 0.13^{b}$ & $2.04 \pm 0.67^{b}$ & $99.88 \pm 0.43^{\mathrm{a}}$ \\
\hline $\boldsymbol{P}$. spp. & $99.83 \pm 0.03^{\mathrm{a}}$ & $99.65 \pm 0.1^{\mathrm{a}}$ & $7.84 \pm 0.1^{\mathrm{a}}$ & $6.22 \pm 0.16^{\mathrm{a}}$ & NT & $99.76 \pm 0.39^{\mathrm{a}}$ \\
\hline P. spp. & $99.83 \pm 0.03 \mathrm{a}$ & $99.65 \pm 0.1 \mathrm{a}$ & $7.84 \pm 0.1 \mathrm{a}$ & $6.22 \pm 0.1$ & NT & $99.76 \pm 0.39 \mathrm{a}$ \\
\hline
\end{tabular}

\section{Effect of incubation time on decolorization of dyes}

Time is one major contributory factor on decolorization of dyes with different bacterial isolates. The decolorization of tested dyes differed significantly when treated with different isolates and at different incubation time in shake flask experiments. Generally, decolorization trends were quite high within 2-8 days in most of the cases studied (Fig. 2, 3 \&4). UV-Vis scan (300-700 nm) of supernatants from batch cultures at different time intervals showed a decrease in peak at the respective absorption maxima of all the three dyes. For Food Red and Congo red dyes, peaks observed at its respective absorption maxima wavelength were decreased without any shift in $K$ max up to complete decolorization of the dye in the culture (8 days) in comparison with dye concentrations at initial incubation time (Fig. $2 \& 3$ ). While Brilliant yellow dye peak observed 
at its respective absorption maxima wavelength was decreased with a little shift in $K$ max up to complete decolorization of the dye in the culture ( 8 days) in comparison with dye concentration at initial incubation time (Fig. 4).

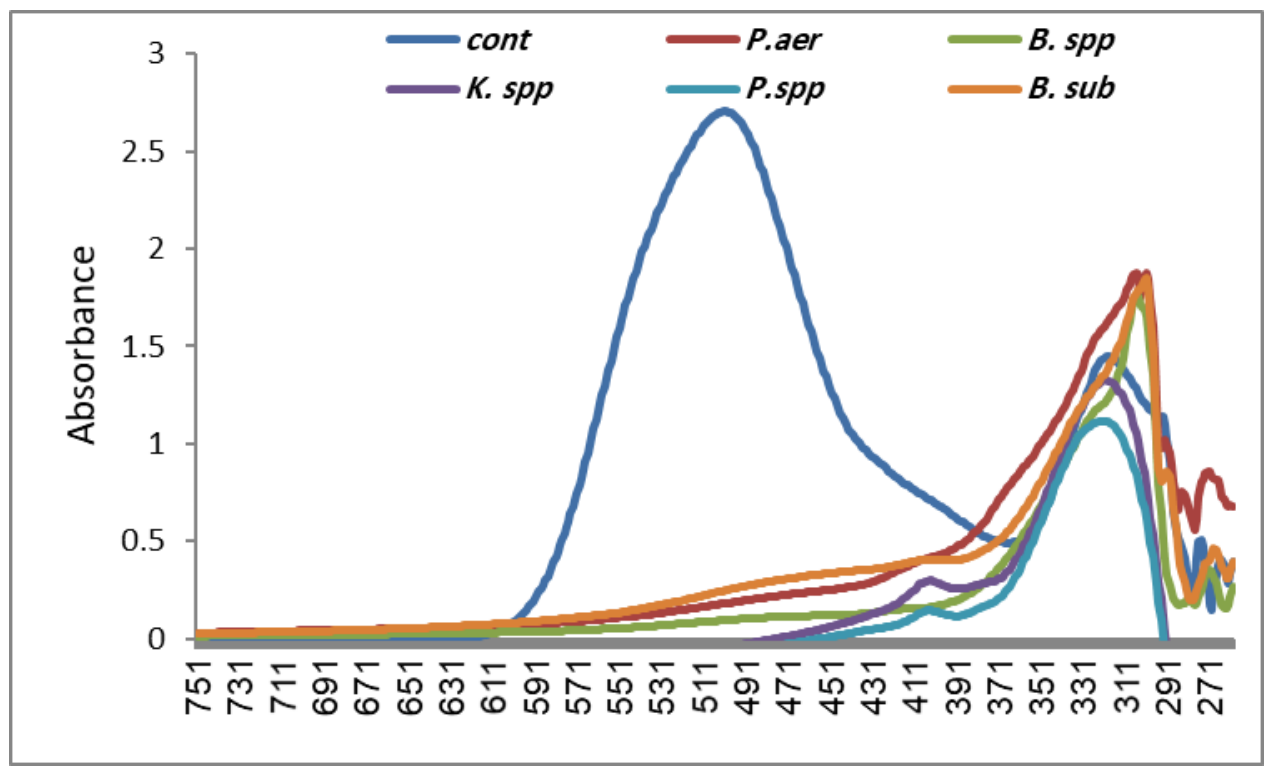

Fig. 2. Variation in the UV-Vis spectra of A: $0.2 \%$ of Food Red and control decolorization by B. sub.: Bacillus subtilis, P. aer.: Pseudomonas aeruginosa, B. spp.: Bacillus spp., K. spp.: Klebsiella spp., P. spp.: Proteus spp. after 8 days.

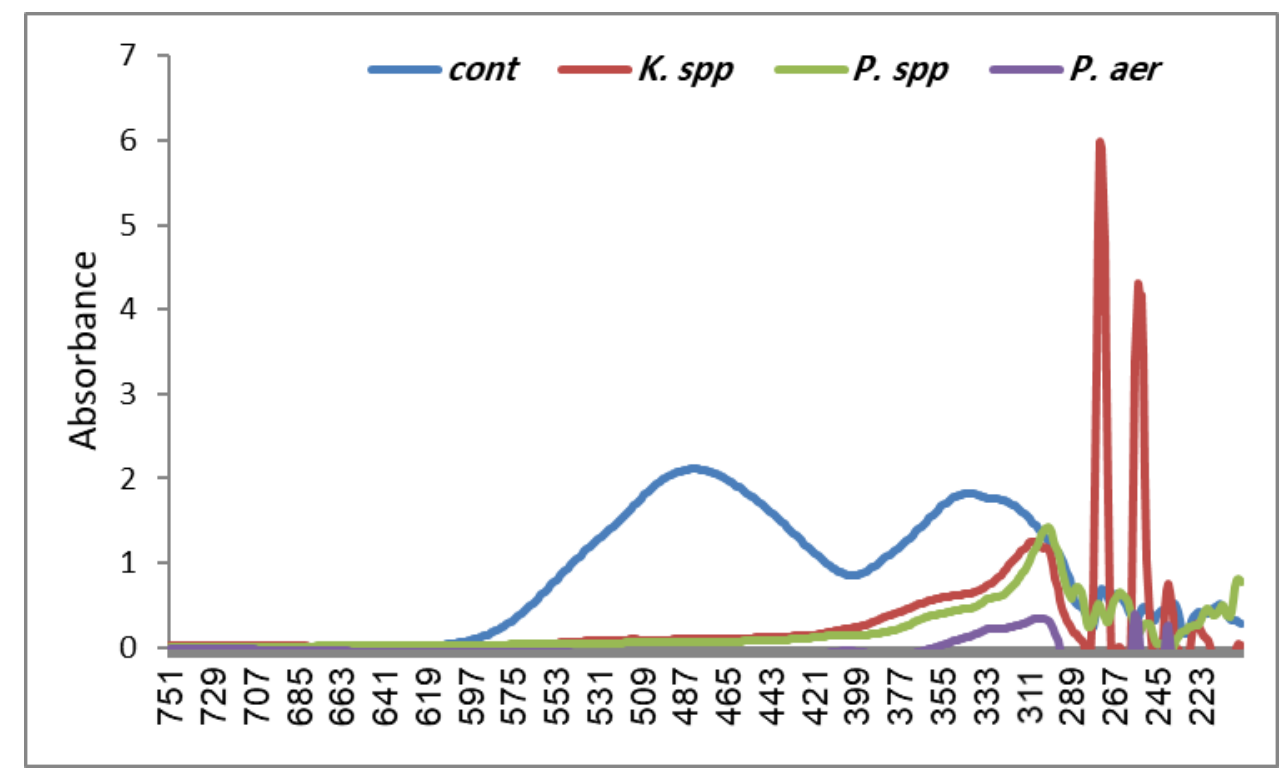


Fig. 3. Variation in the UV-Vis spectra of control and Congo red dye (50 $\mathrm{ppm})$ decolorization by B. sub.: Bacillus subtilis, P. aer.: Pseudomonas aeruginosa, B. spp.: Bacillus spp., K. spp.: Klebsiella spp., P. spp.: Proteus spp. after 8 days.

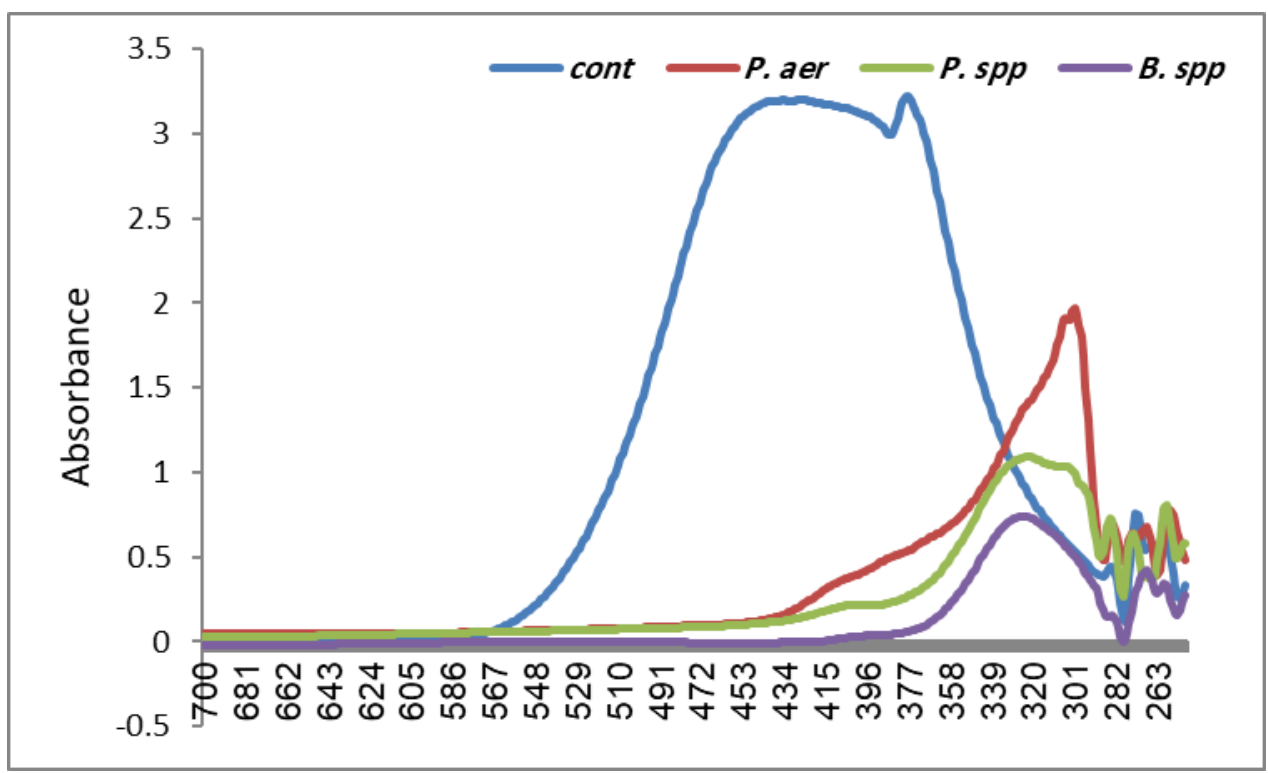

Fig. 4. Variation in the UV-vis spectra of control and Brilliant yellow (50 ppm) decolorization by B. sub.: Bacillus subtilis, P. aer.: Pseudomonas aeruginosa, B. spp.: Bacillus spp., K. spp.: Klebsiella spp., P. spp.: Proteus spp. after 8 days.

\section{Effect of initial concentration of dye}

For Brilliant yellow, as the concentration of dye was increased (25-100 ppm), the rate of decolorization by P. ear., P. spp. and B. spp. varied from 99.88 to $20.32 \%$. When the dye concentration was as high as $100 \mathrm{ppm}$, almost $66.21 \%, 20.32 \%$ and $25.26 \%$ of the dye was removed by P. ear., P. spp. and B. spp. respectively after 8 days (Figure 5). This suggests that a significant high color removal can be achieved by the $\mathrm{P}$. ear. $(\mathrm{P}<0.05)$ as compared with other tested isolates. Similar results were observed for Congo red where the rate of decolorization was dropped markedly as the concentration increased from $25 \mathrm{ppm}$ to $100 \mathrm{ppm}$ (Fig. 6). In comparison with tested isolates,

K. spp. was exhibited significantly the highest color removal in which decolorization rate exceeded $72 \%(\mathrm{P}<0.05)$ (Fig. 6). On the other hand, no significant decolorization rate was observed as the concentration of Food Red dye raised from 0.1-0.4\% after 8 days (Figure 7) $(\mathrm{P}>0.05)$. 
Vol. 4, No. 05; 2019

ISSN: $2456-8643$

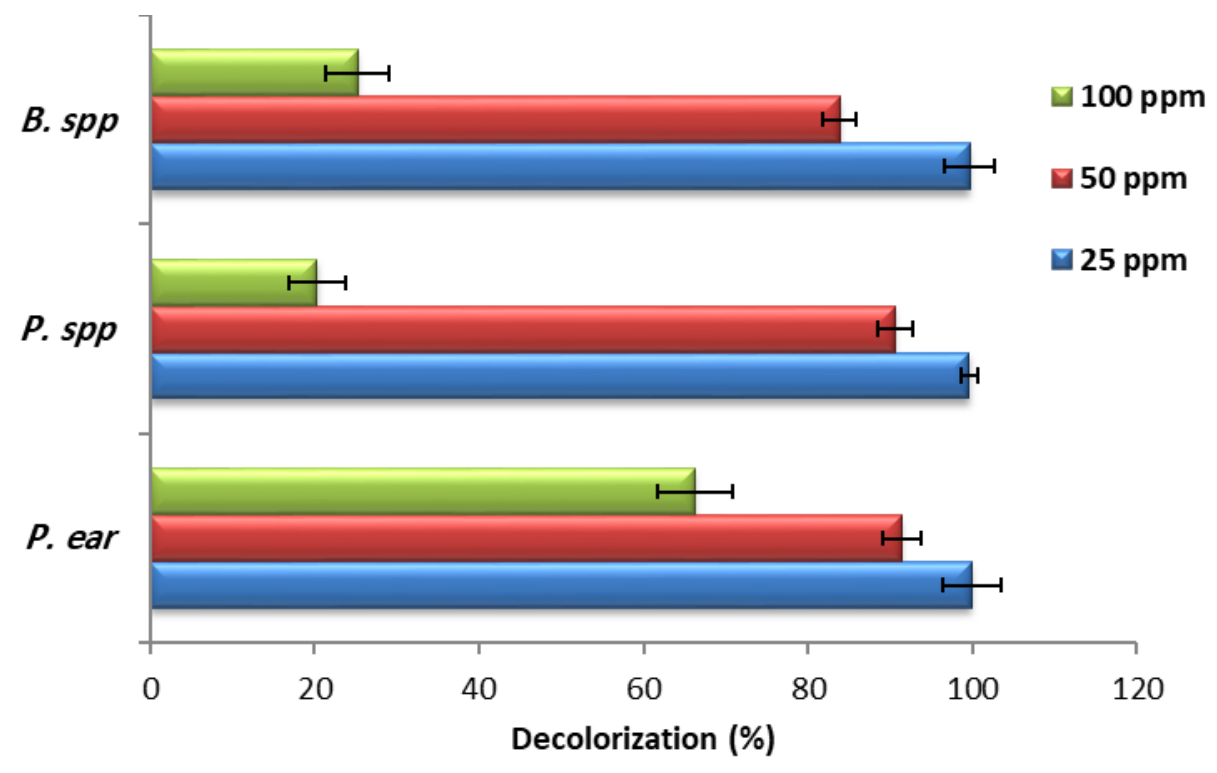

Fig. 5. Percentage decolorization of Brilliant yellow dye at various dye concentrations (ppm) by different bacterial isolates after 8 days. P. aer.: Pseudomonas aeruginosa, B. spp.: Bacillus spp., P. spp.: Proteus spp. Data are expressed as the mean \pm standard deviation (SD) of three replicates

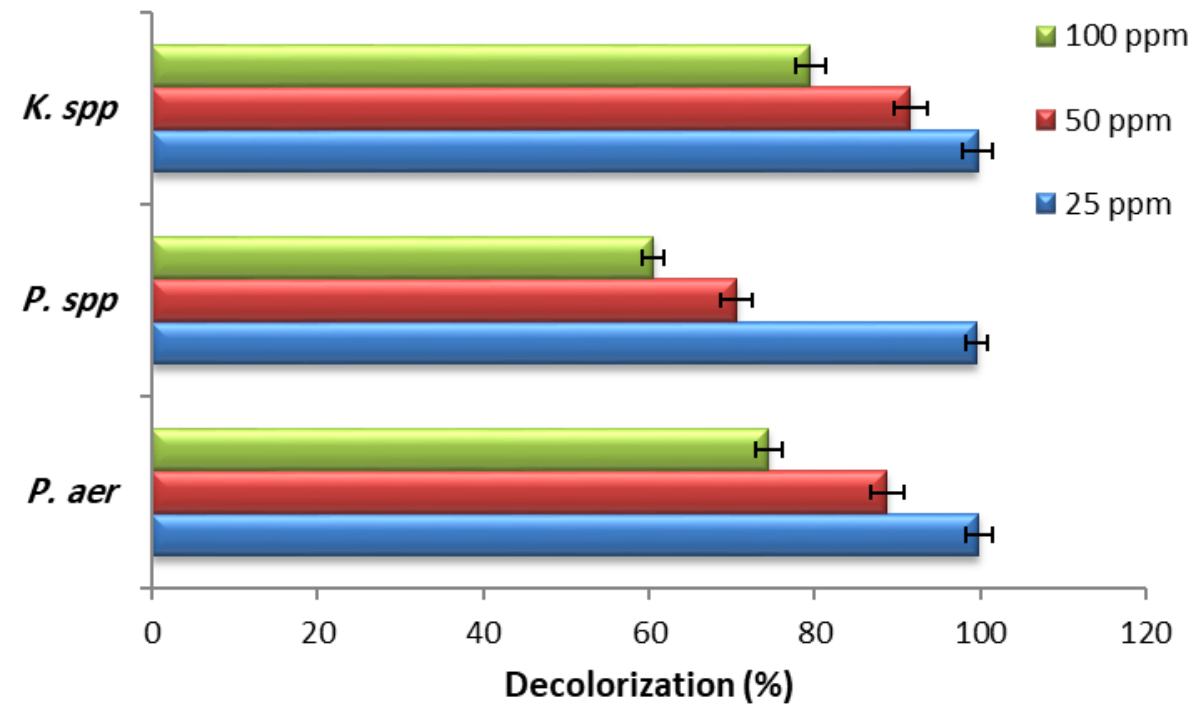

Fig. 6. Percentage decolorization of Congo Red dye at various dye concentrations (ppm) by different bacterial isolates. P. aer.: Pseudomonas aeruginosa, K. spp.: Klebsiella spp., P. spp.: Proteus spp. Data are expressed as the mean \pm standard deviation (SD) of three replicates. 


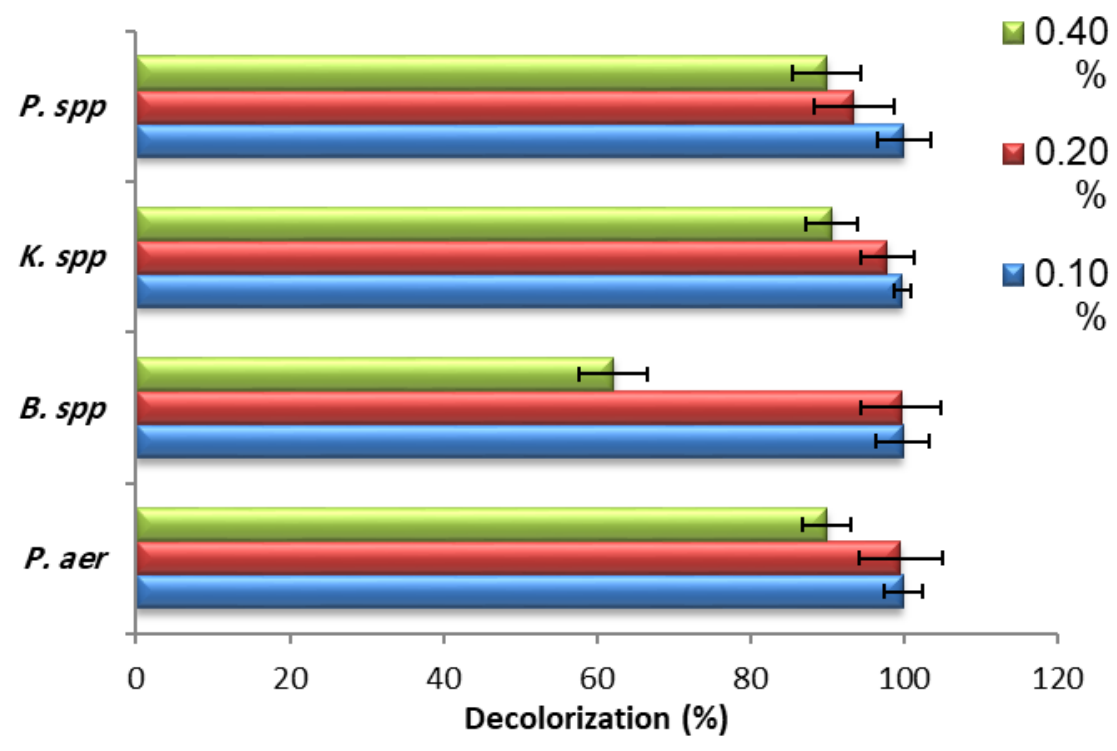

Fig. 7. Percentage decolorization of Red Food dye at various dye concentrations $(0.1 \%, 0.2 \%$, $0.4 \%$ ) by different bacterial isolates. P. aer.: Pseudomonas aeruginosa, B. spp.: Bacillus spp., K. spp.: Klebsiella spp., P. spp.: Proteus spp. Data are expressed as the mean \pm standard deviation (SD) of three replicates.

\section{DISCUSSION}

There is an increasing interest in bacteria as bioderading agents due to their potential to transform and degrade most synthetic dyes effectively $[15,16]$. This study revealed the potential of bacterial isolates: Bacillus subtilis, Pseudomonas aeruginosa, Bacillus spp., Klebsiella spp, Proteus spp in the removal of dyes: Brilliant yellow, Congo red, and Red Food . In addition, the effect of some environmental factors on dye decolorization by bacteria was investigated.

The environmental factors including $\mathrm{pH}$, dye concentration and temperature are important on the biodegradation activity of bacteria. Decolorization of synthetic dyes by bacteria is often related to enzymatic reaction [17] and enzymes are highly sensitive to $\mathrm{pH}$ in the medium. Most dyes including azo dyes are completely decolorized by bacteria where $\mathrm{pH}$ is not exceed 7.1 (neutral) which was in parallel with current results [18]. Also, it has been reported that rate of color removal increased with increasing temperature for some extent [19]. In previous study, the optimum range of temperature was found between $25^{\circ} \mathrm{C}$ to $40^{\circ} \mathrm{C}$ for effective dye removal process by bacterial activity [20]. According to previous studies, $37^{\circ} \mathrm{C}$ was the optimum temperature for Bacillus sp. [21], and Pseudomonas spp. [22]. Moreover, increasing in the dye concentration leading to decreasing the decolorization rate, probably due to the toxic effect of dyes $[2,23]$.

Congo red, Brilliant yellow and Red food are azo dyes are popularly used in the field of industry. These azo dyes are toxic and carcinogenic. Therefore biotreatment of these chemicals were the most environmentally friendly solution to remove them. Aerobic degradation of textile azo dyes by bacterial consortium has been reported [23, 24] and their decolorization depend on the 
oxidation potential of microorganisms. Several studies have reported that Pseudomonas and Bacillus species are the organisms which can be used for azo dye decolorization. The rate of their decolorization was reported above $96 \%$ [25, 26, 27] which was in accordance with present results (Fig. 3 and 4). Also in a preliminary study which was reported that Proteus species exhibited high activity in the decolorization of azo dyes [28, 29].

The use of pure-culture system ensures the reproduction of data and interpretation of the detailed mechanism of dye degradation. However, higher degree of biodegradation and mineralization were achieved when metabolic activities of mixed cultures were tested [30]. The mechanism of microbial decolorization of azo dyes involves the reductive cleavage of azo linkages under anaerobic and aerobic conditions resulting in the formation of colorless aromatic amines, rendering the dye solution colorless. The mechanism of Congo red biodegradation by Pseudomonas has been previously reported [27]. In the current study, a peak decrease at the respective absorption maxima of all the three dyes without change in $\mathrm{pH}$ value indicated that decolorization by bacteria is due to biodegradation, rather than inactive surface adsorption [17, 28] (Fig. 2, 3 \&4).

\section{CONCLUSION}

In this study, the pure cultures of Pseudomonas aeruginosa, Klebsiella spp., and Proteus spp could successfully be used to decolourize Congo red, Brilliant yellow and Food red containing simulated wastewater effluents. Color removal was highly dependent on initial concentration of the dye and higher decolorization (\%) has been observed with lower concentration of dyes. As mixed culture found to be more effective on dye decolorization, using mixed cultures of tested isolates to decolorize Methylene green, Nile blue, and Acridine orange need to be investigated.

\section{ACKNOWLEDGEMENTS}

Authors are grateful to the department of Chemistry, University of Tripoli for the encouragement and research facilities.

\section{REFERENCES}

[15] Arora, P. K., Srivastava, A., Singh, V. P. Bacterial degradation of nitrophenols and their derivatives. J. Hazard Mater. 266: 42 -59, 2014.

[17] Asad S., Amoozegar M. A., Pourbabaee A., Sarbolouki M. N. \& Dastgheib S. M. M. Decolorization of textile azo dyes by newly isolated halophilic and halotolerant bacteria. Bioresource technology. 98(11): 2082-2088. 2007.

[16] Cai P. J., Xiao X., He Y. R., Li W. W., Chu J.,Wu C., He M. X., Zhang Z., Sheng G. P., Lam M. H., Xu F., \& Yu H. Q. Anaerobic biodecolorization mechanism of methyl orange by Shewanella oneidensis MR-1.Appl Microbiol Biotechnol 93:1769-1776, 2011.

[9] Hsueh C. C., Hsu A. W., Chen C. T., Wu C. C., \& Chen B. Y. Comparative assessment of azo dyes and nitroaromatic compounds reduction using indigenous dye-decolorizing bacteria. Journal of the Taiwan Institute of Chemical Engineers. 79:134-140, 2017 
[18] Cui D., Li G., Zhao M. \& Han S. Decolourization of azo dyes by a newly isolated Klebsiella sp. strain Y3, and effects of various factors on biodegradation. Biotechnology \& biotechnological equipment. 28(3): 478-486, 2014.

[28] Fan, L., Zhu, S. N., Liu, D. Q., \& Ni, J. R. Decolorization of 1-amino-4bromoanthraquinone- 2-sulfonic acid by a newly isolated strain of Sphingomonas herbicidovorans. International Biodeterioration \& Biodegradation, 1-5, 2008.

[14] Forgacs E., Cserháti T., \& Oros G. Removal of synthetic dyes from wastewaters: a review.

Environment International. 30(7) :953-971, 2004.

[4] Guaratini C. C. I., \& Zanoni M. V. B. Textile dyes. Quim Nova.23:71-8. 2000.

[25] Gopinath, K. P., Murugesan, S., Abrahamb, J., Muthukumar, K. Bacillus sp. mutant for improved biodegradation of Congo red: random mutagenesis approach. Bioresource Technology. 100:6295-6300, 2009.

[24] Harshad L., Avinash K., Diby P. \& Sanjay G. Biodegradation and detoxification of textile azo dyes by bacterial consortium under sequential microaerophilic/aerobic processes. EXCLI Journal. 14:158-174, 2015.

[26] Hsueh C. C., \& Chen B. Y. Comparative study on reaction selectivity of azo dye decolorization by Pseudomonas luteola. J Hazard Mater 141:842-849, 2007.

[28] Hsueh C. C, Chen B. Y., \& Yen C. Y. Understanding effects of chemical structure on azo dye decolorization characteristics by Aeromonas hydrophila. J Hazard Mater 167:995-1001, 2009.

[13] Kaushik, P., \& Malik, A. Fungal dye decolorization: Recent advances and future potential. Environment International, 35:127-141, 2009.

[22] Kalyani D. C., Patil P. S., Jadhav J. P., \& Govindwar S. P. Biodegradation of reactive textile dye Red BLI by an isolated bacterium Pseudomonas sp. SUK1. Bioresour Technol 99:46354641, 2008.

[11] Kalyani D. C., Telke A. A., Govindwar S. P., \& Jadhav J. P. Biodegradation and detoxification of reactive textile dye by isolated Pseudomonas sp. SUK1. Water Env Res 81:298-307, 2009.

[2] Lu, L., Zhao, M., Liang, S. C., Zhao, L. Y., Li, D. B., \& Zhang, B. B. Production and synthetic dyes decolorization capacity of a recombinant laccase from Pichia pastoris. Journal of Applied Microbiology, 107:1149-1156, 2009.

[20] Madhuri S. \& Girish P. Biomethanation of dye industry wastewater. Univesal journal of environmental research and technology. 2(3): 179-187, 2012. 
[7] Park, C., Lee, M., Lee, B., Kim, S. W., Chase, H. A., \& Lee, J. Biodegradation and biosorption for decolorization of synthetic dyes by Funalia trogii. Biochemical Engineering Journal, 36:59-65, 2007.

[19] Pearce CI, Lloyd JR, , Guthrie JT. The removal of colour from textile wastewater using whole bacterial cells. Dyes and pigments. 2003; 58(3): 179-196.

[8] Perumal K., Malleswari R. B., Catherin A. \& Sambanada Moorthy T. A., Journal of Microbiology and Biotechnology Research, 2:475, 2012.

[10] Parshetti G. K., Parshetii S. G., Telke A. A., Kalyani D. C., Doong R. A. \& Govindwar S. P., Journal of environmental sciences, 23:1384, 2011.

[3] A.A. Pourbabaee, F. Malekzadeh, M.N. Sarbolouki, F. Najafi. Aerobic Decolorization and Detoxification of a Disperse Dye in Textile Effluent by a New Isolate of Bacillus sp.. Biotechnology and Bioengineering, 93(4): 631-635, 2006

[7] Saratale, R. G., Saratale, G. D., Kalyani, D. C., Chang, J. S., \& Govindwar, S. P. Enhanced decolorization and biodegradation of textile azo dye Scarlet $\mathrm{R}$ by using developed microbial consortium-GR. Bioresource Technol 100:2493-2500, 2009.

[1] Saratale R. G., Saratale G. D., Chang J. S., \& Govindwar S. P. Bacterial decolorization and degradation of azo dyes: a review. J Taiwan Inst Chem Eng 42:138-157, 2011.

[5] Singh, P., Birkeland, N. K., Iyengar, L., \& Gurunath, R. Mineralization of 4aminobenzenesulfonate (4-ABS) by Agrobacterium sp. Strain PNS -1. Biodegradation

1572-972, 2006.

[30] Sharma, D. K., Saini, H. S., Singh, M., Chimni, S. S., \& Chadha, B. S. Isolation and characterization of microorganisms capable of decolorizing various triphenylmethane dyes. J. Basic Microbiol. 44 (1):59-65, 2004.

[27] Telke A. A., Joshi S. M., Jadhav S. U., Tamboli D. P., \& Govindwar S. P. Decolorization and detoxification of Congo red and textile industry effluent by an isolated bacterium Pseudomonas sp. SU-EBT. Biodegradation 21:283-296, 2010.

[23] Tony B. D., Goyal D., Khanna S. b. Decolorization of Direct Red 28 by mixed bacterial culture in an up-flow immobilized bioreactor. J Ind Microbiol Biotechnol 36:955-960, 2009.

[21] Velmurugan S. and Ravikumar R. Biodegradation and decolorization of reactive dye red ME4BL by Bacillus subtilis. International journal of environmental bioremediation \& biodegradation. 2014; 2(6), 250-255.

[29] Zhang M. M., Chen W. M., Chen B. Y., Chang C. T., Hsueh C. C., Ding Y., Lin K. L., \& $\mathrm{Xu} \mathrm{H}$. Comparative study on characteristics of azo dye decolorization by indigenous decolorizers. Bioresour Technol 101:2651-2656, 2010. 
International Journal of Agriculture, Environment and Bioresearch

Vol. 4, No. 05; 2019

ISSN: $2456-8643$

[12] Zhou, W., \& Zimmermann, W. Decolorization of industrial effluents containing reactive dyes by actinomycetes. FEMS Microbiology Letters, 107:157-162, 1993. 